\title{
Synthesis of dichloroindium hydride and exploration of its reactivity with organic functional groups. Tandem, selective and partial reductions of halo-nitriles
}

\author{
Jaime Z. Saavedra, Panathda Bayrasy, Angel Resendez, Rachel Snelling, Michael H. \\ Anderson, and Bakthan Singaram* \\ Department of Chemistry and Biochemistry, University of California Santa Cruz, \\ 1156 High Street, Santa Cruz, CA 95064, U.S.A. \\ E-mail: $\underline{\text { Singaram@ucsc.edu }}$
}

Dedicated to Professor Keith Smith on the occasion of his $65^{\text {th }}$ anniversary

\begin{abstract}
Methods for the in situ generation of dichloroindium hydride $\left(\mathrm{HInCl}_{2}\right)$ via the reduction of $\mathrm{InCl}_{3}$ with various reducing agents, such as tributyltin hydride (tributylstannane; $\mathrm{Bu}_{3} \mathrm{SnH}$ ), diisobutylaluminum hydride (DIBAL-H), triethylsilane $\left(\mathrm{Et}_{3} \mathrm{SiH}\right)$, lithium aminoborohydride (LAB), and sodium borohydride $\left(\mathrm{NaBH}_{4}\right)$, in various solvents are reviewed and compared. The use of the $\mathrm{InCl}_{3} / \mathrm{NaBH}_{4}$ system in addition to forming $\mathrm{HInCl}_{2}$, also generated borane that was trapped as $\mathrm{BH}_{3}$-tetrahydrofuran (THF). Carefully controlling the activity of these reducing agents allows for the selective and/or partial reduction of multi-functionalized compounds containing nitriles and halogens.
\end{abstract}

Keywords: Dichloroindium hydride, $\mathrm{HInCl}_{2}, \mathrm{InCl}_{3}, \mathrm{NaBH}_{4}$, borane, reduction

\section{Table of Contents}

1. Introduction

2. Preparation of Dichloroindium Hydride $\left(\mathrm{HInCl}_{2}\right)$

2.1 Generation of $\mathrm{HInCl}_{2}$ using $\mathrm{Bu}_{3} \mathrm{SnH}$

2.2 Generation of $\mathrm{HInCl}_{2}$ using DIBAL-H

2.3 Generation of $\mathrm{HInCl}_{2}$ using silanes

2.4 Generation of $\mathrm{HInCl}_{2}$ using $\mathrm{NaBH}_{4}$

2.5 Generation of $\mathrm{HInCl}_{2}$ using lithium aminoborohydride (LAB)

2.6 Tandem, selective, and partial reduction of nitriles and halides using $\mathrm{HInCl}_{2}$

2.6.1 Tandem reductions using $\mathrm{HInCl}_{2}$ and $\mathrm{BH}_{3}$. THF 
2.6.2 Selective reduction of halides in the presence of nitriles

2.6.3 Tandem, selective, and partial reduction of halo-nitriles using DIBAL-H and $\mathrm{InCl}_{3}$

3. Conclusions

4. References

\section{Introduction}

The use of metal-mediated reactions has played an important role in the development and advancement of organic chemistry with far reaching effects spanning novel laboratory techniques to vital industrial applications. Among the many uses of metals, metal hydride reductions of functional groups are among the most common and useful chemical transformations. Traditional and commonly used metal hydrides like sodium borohydride $\left(\mathrm{NaBH}_{4}\right)^{1}$ and lithium aluminum hydride $\left(\mathrm{LiAlH}_{4}\right)^{2}$ form an integral part of the modern organic chemist's toolbox. While both hydrides are used extensively, the ability of $\mathrm{LiAlH}_{4}$ to reduce most functional groups limits its use in the reduction of multifunctional compounds when selective reduction is desired. Conversely, $\mathrm{NaBH}_{4}$ is a mild reducing agent with limited abilities in the reduction of many functional groups such as nitriles and carboxylic acids. Sodium borohydride is known to selectively reduce ketones and aldehydes in the presence of other functional groups. Many alternatives have recently been developed to safely and selectively reduce several functional groups at will. ${ }^{3}$ Among these alternatives, a variety of Group 13 metal hydride derivatives have been developed over the years, some of which are extensively utilized. ${ }^{4}$ Indium has recently garnered attention in metal-mediated reactions due in part to the relatively low oxidation potentials of the most common oxidation states of indium: $\operatorname{In}^{+}(0.14 \mathrm{~V})$ and $\operatorname{In}^{3+}$ $(0.44 \mathrm{~V}) .^{5}$ These oxidation potentials tend to produce favorable reaction conditions for the synthesis of organoindium compounds under ambient conditions.

Indium hydride reagents $\left(\mathrm{LinhH}_{4}, \mathrm{LiPhInH}_{3}\right.$, and $\left.\mathrm{LiPh}_{2} \mathrm{InH}_{2}\right)$ were first prepared from $\mathrm{InCl}_{3}$ and $\mathrm{LiH}$ by Wiberg and $\mathrm{Schmidt}^{6}$ and were later explored by Butsugan and coworkers who further demonstrated their ability to reduce a variety of functional groups including aldehydes, ketones, esters, and halides. ${ }^{7}$ Subsequently, other indium hydride reagents have been developed. In the next section, we give an overview of the generation of dichloroindium hydride $\left(\mathrm{HInCl}_{2}\right)$ and its application to various reductions in organic synthesis.

\section{Preparation of Dichloroindium Hydride $\left(\mathrm{HInCl}_{2}\right)$}

\subsection{Generation of $\mathrm{HInCl}_{2}$ using $\mathrm{Bu}_{3} \mathrm{SnH}$}

Dichloroindium hydride was first prepared by Baba and coworkers by the reduction of $\mathrm{InCl}_{3}$ with tributyltin hydride (tributylstannane; $\mathrm{Bu}_{3} \mathrm{SnH}$ ) (Scheme 1). ${ }^{8}$ 


$$
\mathrm{InCl}_{3}+\mathrm{Bu}_{3} \mathrm{SnH} \underset{-78^{\circ} \mathrm{C}, 10 \text { min }}{\stackrel{\mathrm{THF}}{\longrightarrow}} \mathrm{HInCl}_{2}+\mathrm{Bu}_{3} \mathrm{SnCl}
$$

Scheme 1. Generation of dichloroindium hydride. ${ }^{8}$

The in situ generated $\mathrm{HInCl}_{2}$ arising from the reduction of $\mathrm{InCl}_{3}$ with $\mathrm{Bu}_{3} \mathrm{SnH}$ was able to reduce a variety of functionalities including aldehydes, ketones and alkyl halides. ${ }^{8}$ Interestingly, the $\mathrm{InCl}_{3} / \mathrm{Bu}_{3} \mathrm{SnH}$ system was found to effect stereoselective reductive aldol reactions affording both syn and anti selectivity depending on the solvent used (Scheme 2). ${ }^{9}$

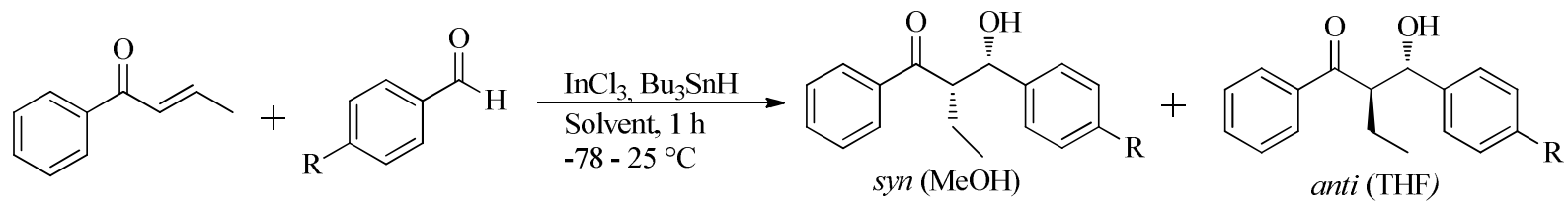

Scheme 2. Selective reductive aldol reactions of $\alpha, \beta$-unsaturated ketones. ${ }^{9}$

The use of anhydrous THF favored the anti product (syn:anti 5:95), while the use of methanol or $\mathrm{H}_{2} \mathrm{O} / \mathrm{THF}$ favored the syn derivative (syn:anti 99:1 and 95:5 respectively). Additionally, acid chlorides have been partially reduced to the corresponding aldehyde in the presence of triphenylphosphine $\left(\mathrm{PPh}_{3}\right)$ along with $\mathrm{HInCl}_{2}$ generated using a catalytic amount of $\mathrm{InCl}_{3}$ and one equivalent of $\mathrm{Bu}_{3} \mathrm{SnH}$ (Scheme 3). ${ }^{10}$

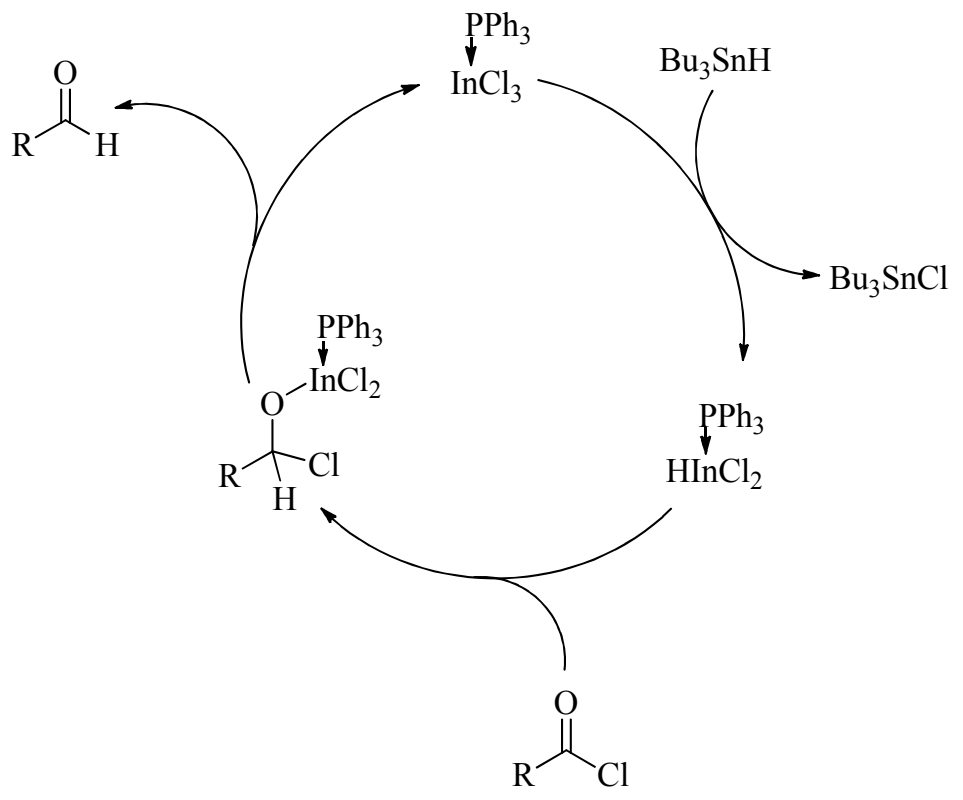

Scheme 3. Proposed catalytic cycle for acid chloride reductions. ${ }^{10}$ 
The catalytic cycle proposed by Baba and coworkers proceeds via the coordination of $\mathrm{PPh}_{3}$ to $\mathrm{InCl}_{3}$ followed by a hydride transfer from the $\mathrm{Bu}_{3} \mathrm{SnH}$ to the $\mathrm{InCl}_{3}$ to generate $\mathrm{HInCl}_{2}$, which then reduces the acid chloride to the corresponding aldehyde and regenerates the $\mathrm{InCl}_{3}{ }^{10}$ Dichloroindium hydride was also found to be an efficient radical initiator catalyzing the reduction of organic halides (Table 1). ${ }^{11 \mathrm{a}}$

Table 1. $\mathrm{InCl}_{3} / \mathrm{Bu}_{3} \mathrm{SnH}$ reduction of halides ${ }^{11 \mathrm{a}}$

$$
\mathrm{R}^{-\mathrm{X}} \underset{\mathrm{THF}, \mathrm{rt}}{\stackrel{\mathrm{Bu}_{3} \mathrm{SnH}}{\longrightarrow}} \mathrm{R}^{-\mathrm{H}}
$$

\begin{tabular}{|c|c|c|c|}
\hline Entry & Halide & $\begin{array}{c}\text { Time } \\
\text { (h) }\end{array}$ & $\begin{array}{c}\text { Yield } \\
(\%)\end{array}$ \\
\hline 1 & 1-bromododecane & 2.0 & 83 \\
\hline 2 & & 2.0 & 79 \\
\hline 3 & & 2.5 & 12 \\
\hline $4^{\mathrm{a}}$ & & 5 & 90 \\
\hline $5^{b}$ & & 5 & 61 \\
\hline
\end{tabular}

${ }^{a} \mathrm{InCl}_{3} 0.1 \mathrm{mmol}, \mathrm{Bu}_{3} \mathrm{SnH} 1 \mathrm{mmol}, \mathrm{RX} 1 \mathrm{mmol}$, THF $2 \mathrm{~mL}, \mathrm{rt} .{ }^{\mathrm{b}} \mathrm{Bu}_{3} \mathrm{SnH}$ (3 mmol) was used

The proposed catalytic cycle for the reduction of organic halides suggests a radical dehalogenation mechanism wherein the In-H bond is cleaved to allow formation of the indium radical, which then reacts with organic halides (Scheme 4). ${ }^{11 \mathrm{a}}$ 


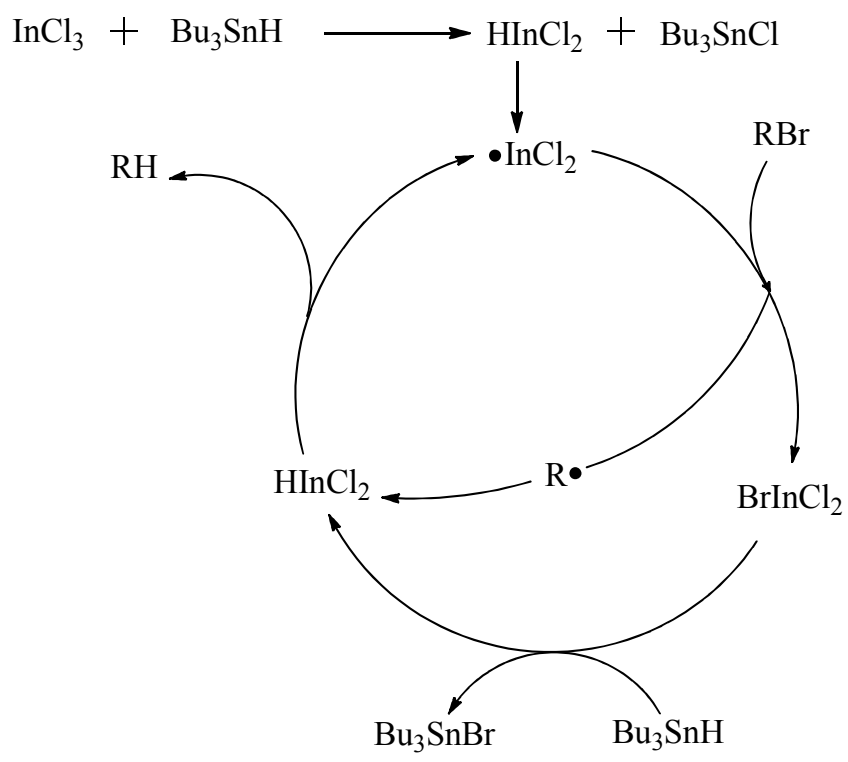

Scheme 4. Proposed catalytic cycle for the dehalogenation of organic halides. ${ }^{11 a}$

More recently, this system has been effectively used in the generation of allylic indium through the hydroindation of 1,3-dienes that react with carbonyl or imine compounds in a onepot reaction sequence. ${ }^{1 \mathrm{~b}}$ For example, 1,4-diphenyl-1,3-butadiene underwent hydroindation and upon the addition of an aliphatic aldehyde, 3-phenylpropanal, gave the allylated product in $88 \%$ yield. ${ }^{11 \mathrm{~b}}$ However, because of the toxicity of $\mathrm{Bu}_{3} \mathrm{SnH}$, alternative reducing agents should be considered to obtain $\mathrm{HInCl}_{2}$.

\subsection{Generation of $\mathrm{HInCl}_{2}$ using DIBAL-H}

Oshima and coworkers developed an alternative method of generating $\mathrm{HInCl}_{2}$ using diisobutylaluminum hydride (DIBAL-H) as the hydride source to reduce $\mathrm{InCl}_{3}$ (Scheme 5). ${ }^{12}$ Dichloroindium hydride was produced and used along with triethylborane $\left(\mathrm{Et}_{3} \mathrm{~B}\right)$ to carry out the hydroindation of a variety of alkynes to the corresponding (Z)-alkenes (Table 2). ${ }^{12}$

$$
\mathrm{InCl}_{3}+\text { DIBAL-H } \underset{-78^{\circ} \mathrm{CHF}, 30 \text { min }}{\longrightarrow} \mathrm{HInCl}_{2}+\text { DIBAL-Cl }
$$

Scheme 5. Generation of $\mathrm{HInCl}_{2}$ with DIBAL-H. ${ }^{12}$

Oshima suggests that the addition of $\mathrm{Et}_{3} \mathrm{~B}$ promotes the reaction by acting as a radical initiator that facilitates the radical addition of $\mathrm{HInCl}_{2}$ across the carbon-carbon triple bond. Additionally, $\mathrm{HInCl}_{2}$ and $\mathrm{Et}_{3} \mathrm{~B}$ in the presence of dioxygen were found to promote radical cyclizations via the generation of an ethyl radical, which then reacts with $\mathrm{HInCl}_{2}$ to provide an indium-centred radical $\cdot \mathrm{InCl}_{2} \cdot{ }^{13}$ The generated $\cdot \mathrm{InCl}_{2}$ then reacts with iodine to form the radical 
intermediate 2 which subsequently cyclizes to afford $\mathbf{3}$ followed by a hydrogen atom abstraction from $\mathrm{HInCl}_{2}$ to regenerate $\cdot \mathrm{InCl}_{2}$ and afford the final product 4 (Scheme 6). ${ }^{13}$

Table 2. Hydroindation of alkynes followed by iodolysis ${ }^{\text {a } 12}$

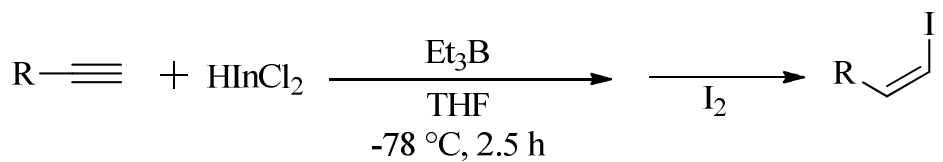

\begin{tabular}{llll}
\hline Entry & $\mathrm{R}$ & $\%$ Yield & $E / Z^{\mathrm{b}}$ \\
\hline 1 & $\mathrm{PhCH}_{2} \mathrm{O}\left(\mathrm{CH}_{2}\right)_{3}$ & 79 & $1 / 99$ \\
2 & $\mathrm{EtOOC}\left(\mathrm{CH}_{2}\right)_{6}$ & 99 & $<1 / 99$ \\
3 & $\mathrm{HO}\left(\mathrm{CH}_{2}\right)_{4}$ & 57 & $<1 / 99$ \\
$4^{\mathrm{a}}$ & $\mathrm{CH}_{2}=\mathrm{CH}_{\left(\mathrm{CH}_{2}\right)_{8}}$ & 74 & $1 / 99$ \\
$5^{\mathrm{b}}$ & $\mathrm{Ph}$ & 99 & $7 / 93$ \\
\hline
\end{tabular}

${ }^{\mathrm{a}}$ Alkyne $(1.0 \mathrm{mmol}), \mathrm{HInCl}_{2}(1.3 \mathrm{mmol})$, and $\mathrm{Et}_{3} \mathrm{~B}(0.20 \mathrm{mmol})$ were used. ${ }^{\mathrm{b}}$ Determined by ${ }^{1} \mathrm{H}$ NMR.

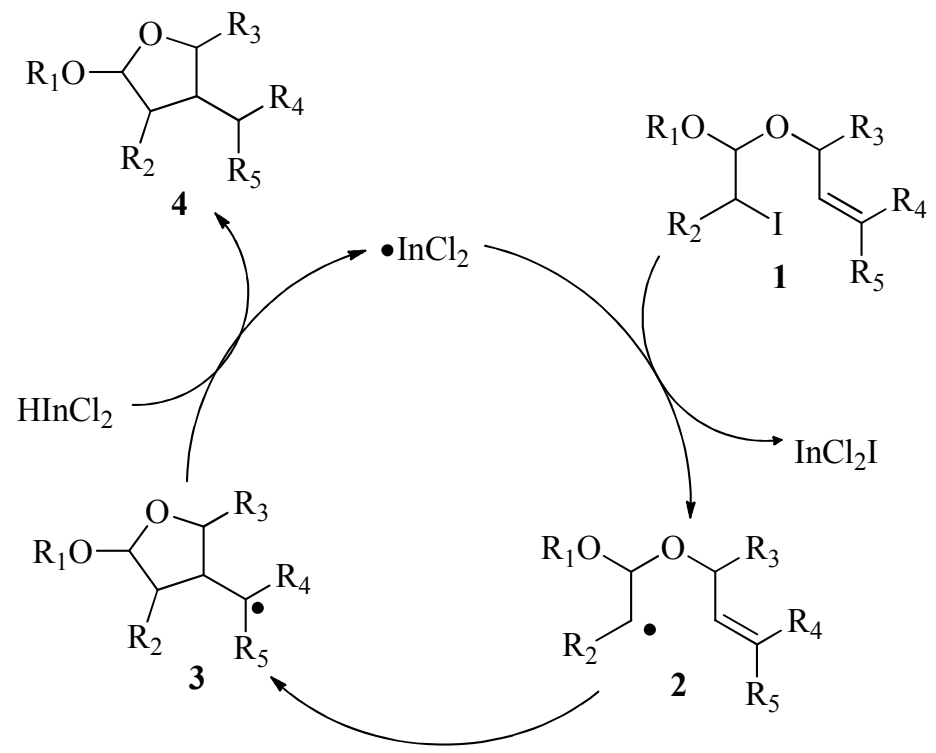

Scheme 6. Proposed catalytic cycle of the radical cyclizations of halo acetals. ${ }^{13}$

Chemoselective reductions of alkyl bromides and carbonyl functionalities using $\mathrm{HInCl}_{2}$ were also explored. ${ }^{13}$ Interestingly, alkyl bromides were found to undergo exclusive reduction in the presence of ester and ketone functionalities, but aldehydes were found to undergo reduction faster than alkyl bromides. ${ }^{13}$ 


\subsection{Generation of $\mathrm{HInCl}_{2}$ using silanes}

Mixtures of silanes and $\mathrm{InCl}_{3}$ have also been used to carry out a variety of reductions. The combination of chlorodimethylsilane and $\mathrm{InCl}_{3}$ was first used to catalyze the reductive FriedelCrafts alkylation of various aromatics with carbonyl compounds (Scheme 7). ${ }^{14}$

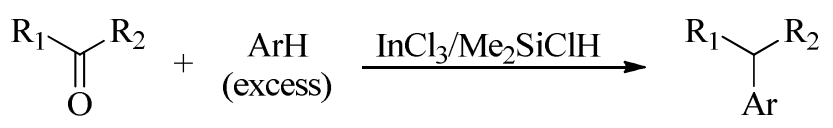

Scheme 7. Friedel-Crafts alkylation with aromatic carbonyl compounds. ${ }^{14}$

Subsequently, reductive deoxygenation of aryl ketones was achieved using chlorodimethylsilane and $\mathrm{InCl}_{3}$ (Scheme 8). ${ }^{15}$

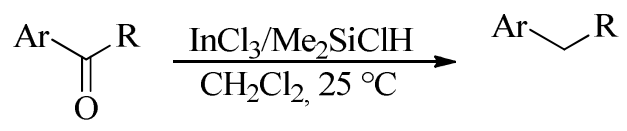<smiles>CC(=O)c1ccc(Cl)cc1</smiles>

$2 \mathrm{~h}, 91 \%$<smiles>O=C(c1ccccc1)c1ccccc1</smiles><smiles>CCC(=O)c1ccccc1</smiles><smiles>CC(=O)c1ccc2ccccc2c1</smiles>

$1 \mathrm{~h}, 55 \%$<smiles>CC(=O)c1ccc(C#N)cc1</smiles>

Scheme 8. Reductive deoxygenation of various ketones. ${ }^{15}$

This mixture of chlorodiphenylsilane and $\mathrm{InCl}_{3}$ has also been shown to bring about analogous reductive deoxygenations of a variety of secondary and tertiary alcohols (Scheme 9). ${ }^{16}$

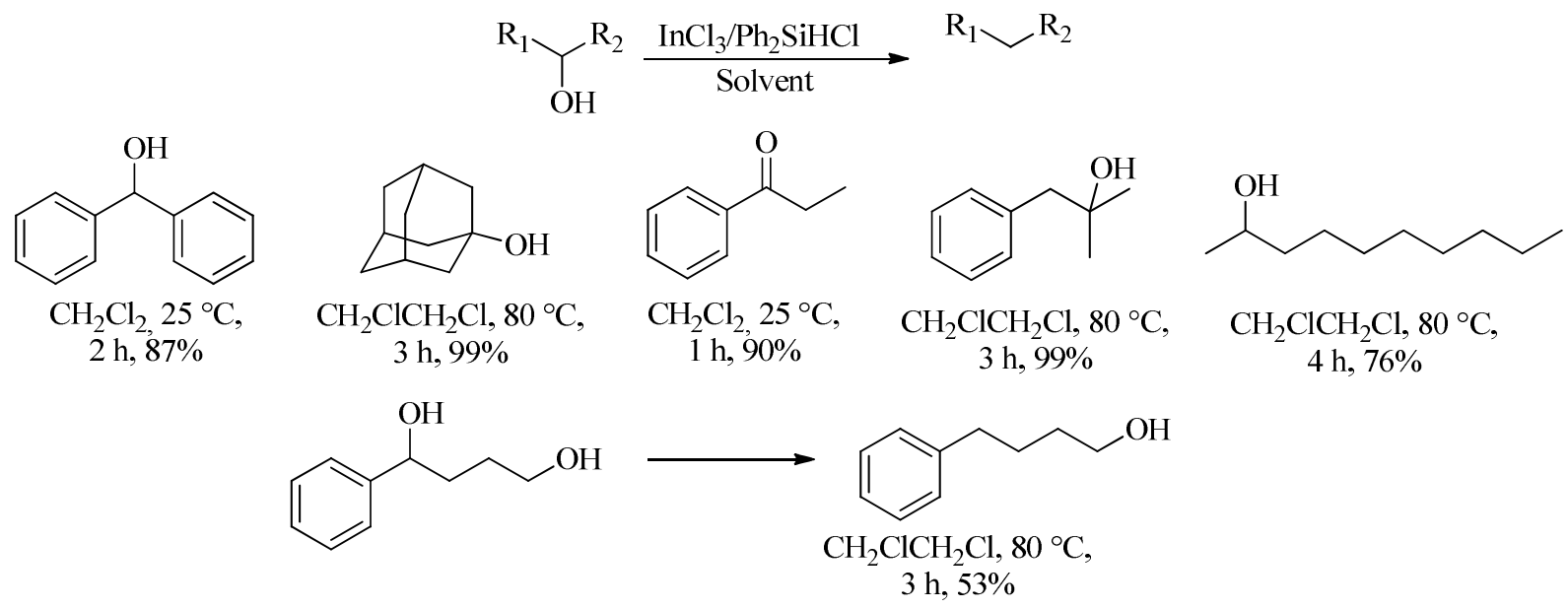

Scheme 9. Reduction of various alcohols. ${ }^{16}$ 
Additionally, the system was found to give high chemoselectivity for hydroxyl groups in the presence of other functional groups, such as esters, as exemplified by the selective deoxygenation of hydroxy-esters (Scheme 10). ${ }^{16}$
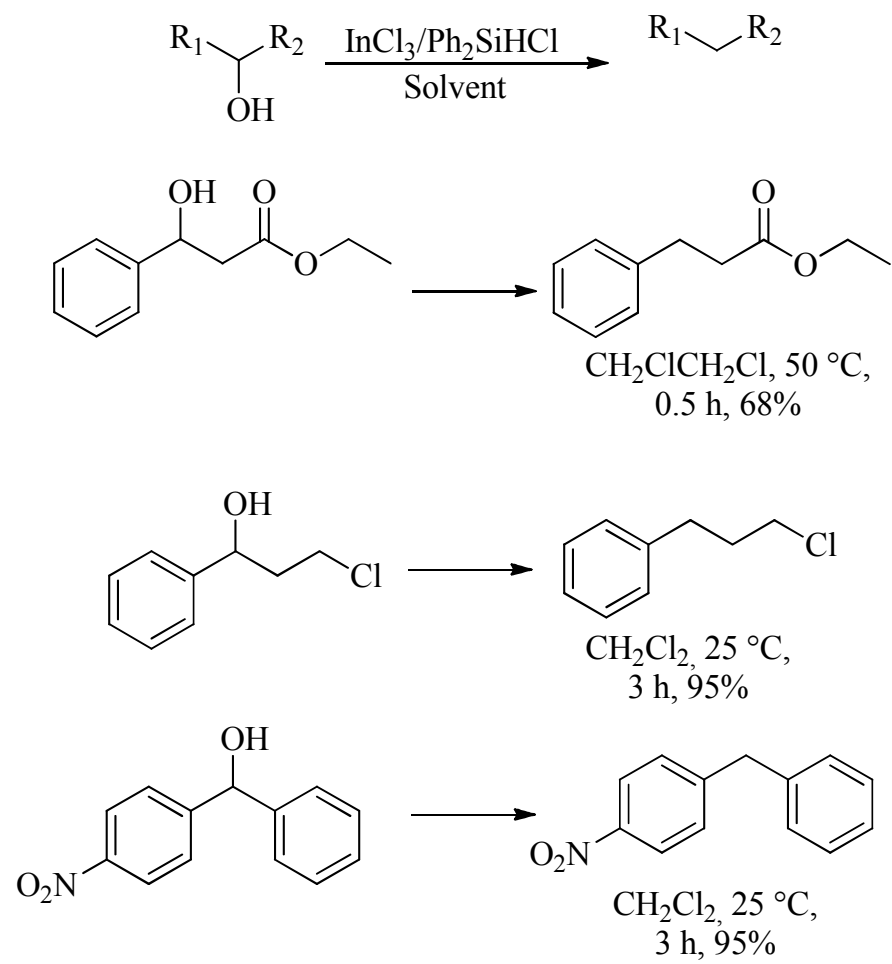

Scheme 10. Direct chemoselective reduction of alcohols by $\mathrm{Ph}_{2} \mathrm{SiHCl} / \mathrm{InCl}_{3}{ }^{16}$

It was proposed that $\mathrm{InCl}_{3}$ acts as a Lewis acid that loosely coordinates to oxygen to accelerate the deoxygenation of the resulting intermediate by promoting a hydride transfer from silane. ${ }^{16}$ While the generation of $\mathrm{HInCl}_{2}$ was not reported in these earlier studies, the in situ formation of $\mathrm{HInCl}_{2}$ may also explain the observed reductions. Later studies of $\mathrm{InCl}_{3}$ with other silanes including triethylsilane $\left(\mathrm{Et}_{3} \mathrm{SiH}\right)$, have proposed the in situ generation of $\mathrm{HInCl}_{2}$ and its use in reductive aldol reactions (Scheme 11). ${ }^{17}$<smiles>CCC(C(=O)c1ccccc1)C(OC)C(CC)C(=O)c1ccc(OC)cc1</smiles>

Scheme 11. Diastereoselective aldol reactions. ${ }^{17}$

Interestingly, $\mathrm{InBr}_{3}$ was also found to undergo a similar reduction in the presence of $\mathrm{Et}_{3} \mathrm{SiH}$ to generate $\mathrm{HInBr}_{2}$ which was used in a variety of diastereoselective reductive aldol reductions. ${ }^{17}$ 
Mechanistically, it was suggested that $\mathrm{HInX}_{2}$ is generated by the slow transmetallation of $\operatorname{In} \mathrm{X}_{3}$ with $\mathrm{Et}_{3} \mathrm{SiH}$ which then undergoes a 1,4-addtion to the enone to afford the indium enolate 1. Subsequent reaction of $\mathbf{1}$ with $\mathbf{2}$ via a Zimmerman-Traxler six-membered cyclic transition state ultimately affords the product $\mathbf{4}^{17}$

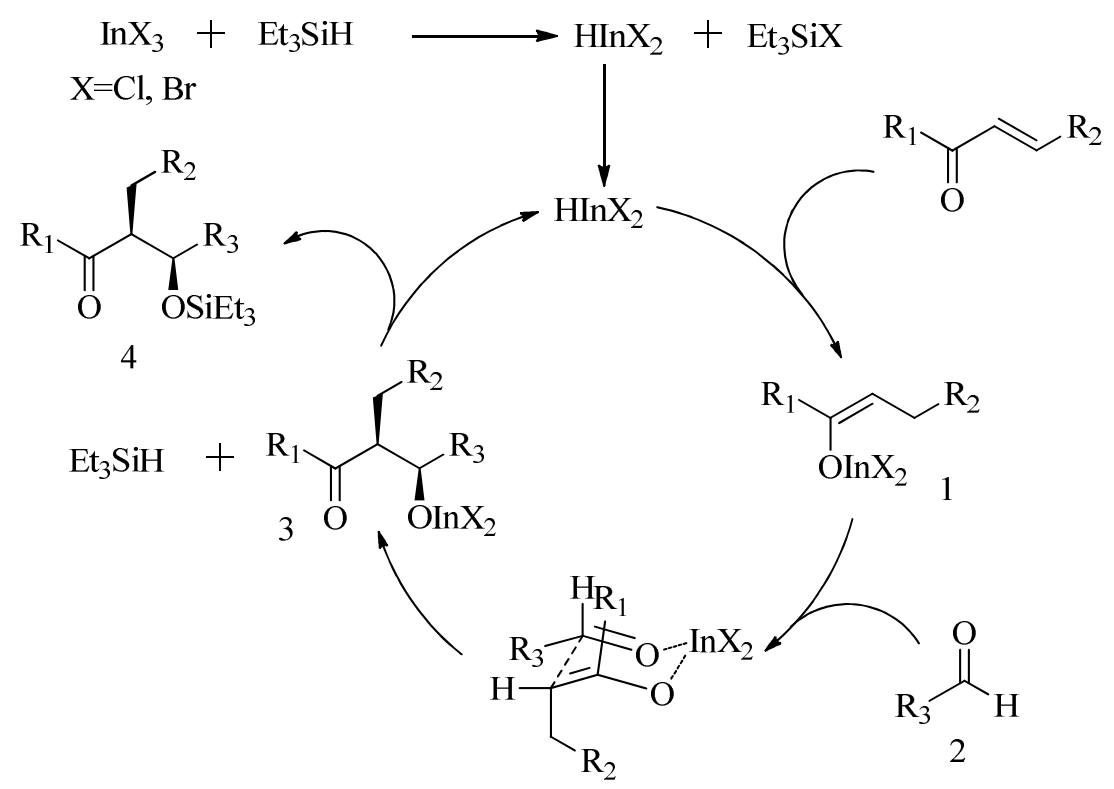

Scheme 12. Plausible mechanistic cycle. ${ }^{17}$

Further exploration of the $\mathrm{InCl}_{3} / \mathrm{Et}_{3} \mathrm{SiH}$ system revealed its ability to reduce alkyl bromides in addition to the intramolecular cyclization of enynes via the hydroindation of alkynes. ${ }^{18}$ The proposed mechanism proceeds via the formation of the vinyl radical which cyclizes to the alkene product. For example, diethyl allylpropargylmalonate afforded the cyclized exo-methylene compound in a 53\% yield (eq. 1, Scheme 13). ${ }^{18 a}$ Additionally, Baba and coworkers have also demonstrated the inter- and intramolecular radical coupling of ene-ynes and halo-alkenes using the $\mathrm{InCl}_{3} / \mathrm{MeONa} / \mathrm{Ph}_{2} \mathrm{SiH}_{2}$ system. ${ }^{18 \mathrm{~b}}$ For example, iodobenzene and acrylonitrile gave the coupled 3-phenylpropanenitrile product in a $60 \%$ yield (eq. 2 , Scheme 13 ). ${ }^{18 \mathrm{~b}}$

The versatility of the $\mathrm{InCl}_{3} / \mathrm{Et}_{3} \mathrm{SiH}$ system to generate $\mathrm{HInCl}_{2}$ has also been extended to the reduction of organic azides to the corresponding amines in a highly chemoselective fashion (Scheme 14). ${ }^{19}$

Additionally, $\gamma$-azidonitriles cyclize to afford pyrrolidin-2-imines (Scheme 15). ${ }^{19}$ The authors propose the $\gamma$-azidonitriles undergo a radical cyclization similar to that of the aforementioned cyclization of enynes.

More recently, the chemoselective reductive amination of carbonyl compounds has also been demonstrated by Yang and coworkers using the $\mathrm{InCl}_{3} / \mathrm{Et}_{3} \mathrm{SiH}$ system (Scheme 16). ${ }^{20}$ 
1.

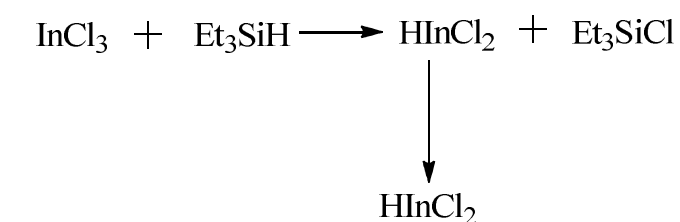<smiles>C#CCC(CC=C)(C(=O)OCC)C(=O)OCC</smiles><smiles></smiles><smiles>CCOC(=O)C1(C(=O)OCC)CC(=CC(C)[In+])C(C)C1</smiles><smiles>C=C1CC(C(=O)OCC)(C(=O)OCC)CC1C</smiles>

$\mathrm{InCl}_{3}+\mathrm{Ph}_{2} \mathrm{SiH}_{2}$

(1 equiv.) (2equiv.)

$\mathrm{NaOMe}$ (1equiv.)

$\mathrm{HInCl}_{2}$

2.

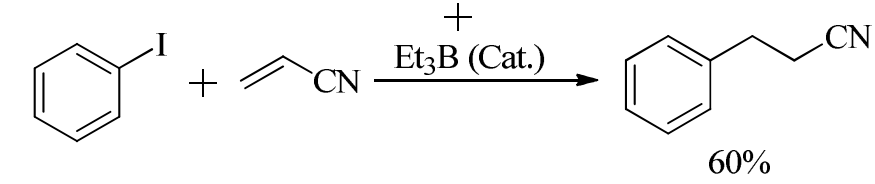

Scheme 13. Cyclization of enynes. ${ }^{18 a, b}$

$$
\begin{array}{ccc}
\mathrm{R}-\mathrm{N}_{3} & \mathrm{InCl}_{3} / \mathrm{Et}_{3} \mathrm{SiH} & \mathrm{R}-\mathrm{NH}_{2} \\
\cline { 2 - 2 }, 0{ }^{\circ} \mathrm{C} & & 55-98 \%
\end{array}
$$

Scheme 14. $\mathrm{HInCl}_{2}$ reduction of azides to primary amines. ${ }^{19}$<smiles>[R]C([R])(C#N)CCN</smiles>

Scheme 15. $\mathrm{HInCl}_{2}$ cyclization of $\gamma$-azidonitriles. ${ }^{19}$<smiles>[R]N[14CH2]N[R1]</smiles>

Scheme 16. Reductive amination of aldehydes and ketones with various amine salts. ${ }^{20}$

The system can be applied to a variety of cyclic, acyclic, aromatic and aliphatic amines in the presence of functionalities such as esters, hydroxyls, carboxylic acids and olefins. NMR and ESI- 
MS were used to help elucidate a mechanism and found the existence of a stable methanolcoordinated indium(III) species which they postulate to be responsible for the generation of indium hydride (Scheme 17). ${ }^{20}$

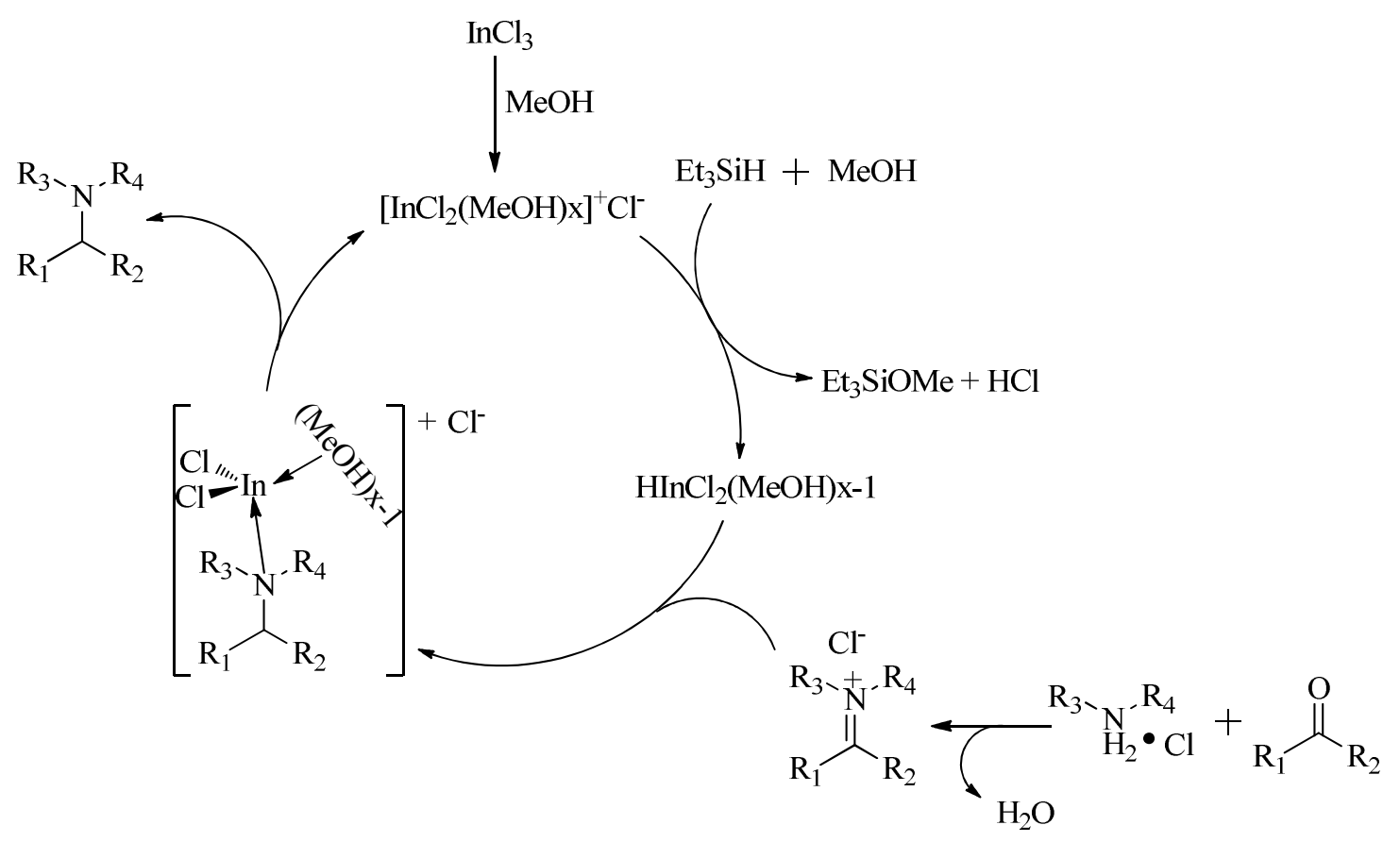

Scheme 17. Proposed mechanism for the $\mathrm{InCl}_{3} / \mathrm{Et}_{3} \mathrm{SiH} / \mathrm{MeOH}$ system-promoted reductive amination. $^{20}$

Sakai and coworkers have further explored the scope of the reductive capabilities of indium hydride with various carbonyl compounds. Tertiary amides were directly reduced to the corresponding tertiary amines using $\mathrm{InBr}_{3} / \mathrm{Et}_{3} \mathrm{SiH}$ (Scheme 18). ${ }^{21}$

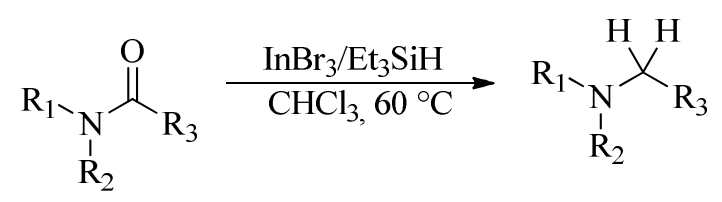

Scheme 18. Reduction of amides to amines. ${ }^{21}$

Interestingly, the reduction of carboxylic acids to primary alcohols or deoxygenation to diphenylmethanes using a similar system with the addition of an aromatic compound has recently been reported. ${ }^{22}$ Aromatic carboxylic acids with the addition of aromatic compounds were fully reduced to the corresponding diphenylmethanes using this system. Sakai and coworkers also describe an efficient method for directly converting carboxylic acids into the corresponding primary alcohols using $\mathrm{InBr}_{3}$ and tetramethyldisiloxane (TMDS) (Scheme 19). ${ }^{22}$ 


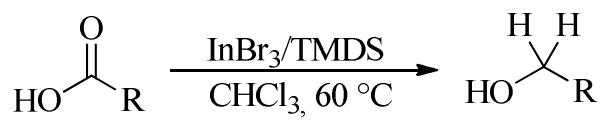

Scheme 19. Synthesis of primary alcohols from aliphatic carboxylic acids. ${ }^{22}$

\subsection{Generation of $\mathrm{HInCl}_{2}$ using $\mathrm{NaBH}_{4}$}

Although $\mathrm{HInCl}_{2}$ has great potential as a mild reducing agent, some of the methods previously used for its synthesis utilize less than ideal conditions and reagents. The $\mathrm{InCl}_{3} / \mathrm{NaBH}_{4}$ reagent system has received significant attention due to the simple and convenient in situ preparation of $\mathrm{HInCl}_{2}{ }^{23} \mathrm{NaBH}_{4}$ is less expensive and a less toxic than $\mathrm{Bu}_{3} \mathrm{SnH}$ originally used to prepare $\mathrm{HInCl}_{2}{ }^{8}{ }^{8}$ Dichloroindium hydride was first generated with $\mathrm{NaBH}_{4}$ by Baba and coworkers when exploring alternative hydride sources to the tin hydride originally used (Scheme 20). ${ }^{23}$

$$
\begin{array}{ccc}
\mathrm{R}-\mathrm{X} & \frac{\mathrm{InCl}_{3} \text { (cat.) } / \mathrm{NaBH}_{4}}{\mathrm{MeCN}, 25^{\circ} \mathrm{C}} & \mathrm{R}-\mathrm{H} \\
\mathrm{X}=\mathrm{Br}, \mathrm{I} & 2 \mathrm{~h} & 83-95 \%
\end{array}
$$

Scheme 20. $\mathrm{HInCl}_{2}$ reduction of halides. ${ }^{23}$

This new system was also used in the representative intramolecular cyclization of 1-allyloxy2-iodobenzene which afforded 3-methyl-2,3-dihydrobenzofuran in 62\% yield (Scheme 21). ${ }^{23}$

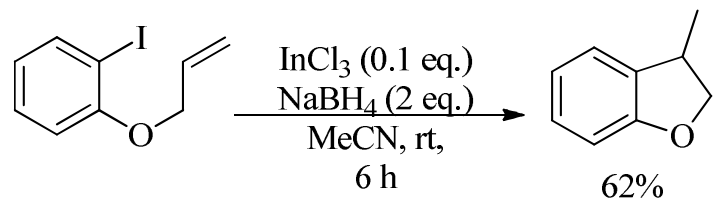

Scheme 21. Intramolecular cyclization of 1-allyloxy-2-iodobenzene. ${ }^{23}$

Representative $\mathrm{InCl}_{3} / \mathrm{NaBH}_{4}$ intermolecular radical additions were also demonstrated using iodobenzene and electron-deficient olefins (Scheme 22). ${ }^{23}$

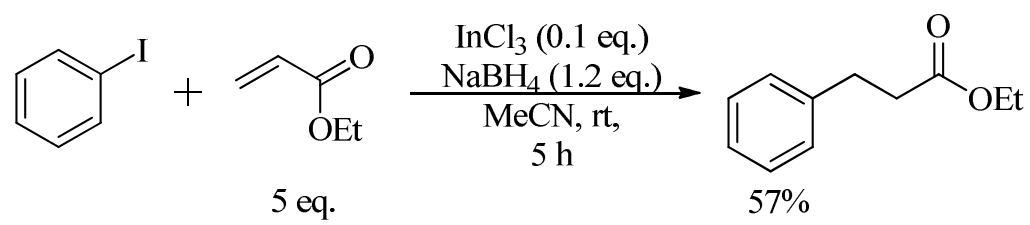

Scheme 22. Radical addition of iodobenzene to electron-deficient olefins. ${ }^{23}$ 
In subsequent work, Ranu and coworkers used the $\mathrm{InCl}_{3 /} \mathrm{NaBH}_{4}$ system to generate $\mathrm{HInCl}_{2}$ and chemoselectively reduced conjugated alkenes (Scheme 23). ${ }^{24,25}$

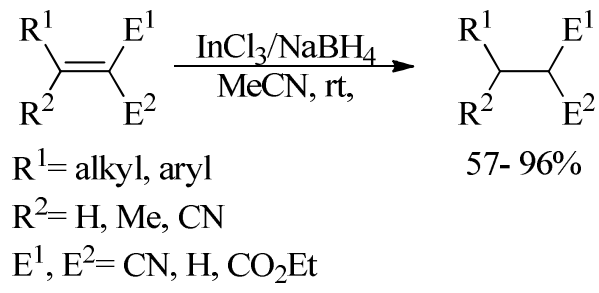

Scheme 23. Reduction of carbon-carbon double bond of conjugated alkenes. ${ }^{24}$

This system was shown to reduce selectively a variety of conjugated alkenes such as, $\alpha, \alpha-$ dicyano olefins, $\alpha, \beta$-unsaturated nitriles, cyanoesters, cyanophosphonate and dicarboxylic esters. Interestingly, the attempted reduction of chalcones produced a mixture of saturated ketones and alcohols when quenched with $\mathrm{H}_{2} \mathrm{O}$ and exclusively saturated alcohols when quenched with $\mathrm{MeOH} .{ }^{24}$ Similarly, Ranu and coworkers also found that the $\mathrm{InCl}_{3} / \mathrm{NaBH}_{4}$ system selectively reduces $\alpha, \beta$-carbon-carbon double bond in $\alpha, \beta: \gamma, \delta$-unsaturated diaryl ketones, dicarboxylic esters, cyano esters and dicyano compounds (Scheme 24$){ }^{26}$

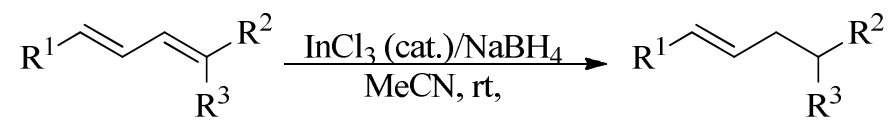

$\mathrm{R}^{2}, \mathrm{R}^{3}=\mathrm{EWG}$

Scheme 24. Selective reduction of $\alpha, \beta$-carbon-carbon double bonds. ${ }^{26}$

Ranu and coworkers have also demonstrated the ability of the $\mathrm{InCl}_{3} / \mathrm{NaBH}_{4}$ system to synthesize $(E)$-alkenes through the stereoselective reduction of vic-dibromides (eq. 1, Scheme $25),{ }^{27}$ as well as the selective reduction of 2,3-epoxybromides to the corresponding allylic alcohols (eq. 2, Scheme 25). ${ }^{28}$ Interesting reactions using alkynes have also been developed using the $\mathrm{InCl}_{3} / \mathrm{NaBH}_{4}$ system, including the dimerization of terminal alkynes to enynes (eq. 3, Scheme 25). ${ }^{29}$

Others have continued to explore the $\mathrm{InCl}_{3} / \mathrm{NaBH}_{4}$ system and its reaction with alkynes. Pan and coworkers have been able to stereoselectively synthesize (E)-2-arylvinylphosphonates through the hydroindation and subsequent hydrolysis of aryl alkyl phosphonates (Scheme 26). ${ }^{30}$ They were able to expand this methodology to the coupling of terminal alkynes with aryl halides to give disubstituted $(E)$-alkenes. ${ }^{31}$

Although a considerable number of studies have examined the $\mathrm{InCl}_{3} / \mathrm{NaBH}_{4}$ system, few have reported on the significant influence that solvent can have on reaction rates and yields of reductions. $^{23,31}$ For example, Baba and coworkers report that alkyl halides were reduced 
efficiently (up to $78 \%$ reduction) using a catalytic amount of $\mathrm{InCl}_{3}$ along with one equivalent of $\mathrm{NaBH}_{4}$ in MeCN (Table 3, entry 4). However, the same reaction is low yielding in THF (only $15 \%$ reduction) under otherwise similar reaction conditions (Table 3 , entry 5 ). ${ }^{23}$ Similar solvent effects were observed by others working with $\mathrm{HInCl}_{2}{ }^{31}$

1.

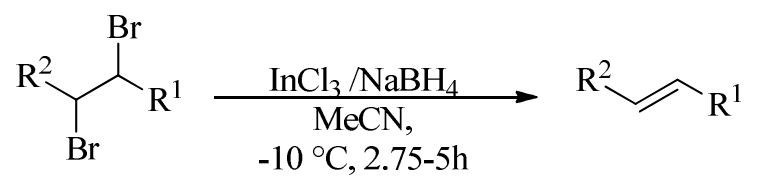

$\mathrm{R}^{1}=$ aryl, alkyl

$\mathrm{R}^{2}=\mathrm{Ph}, \mathrm{CO}_{2} \mathrm{Me}, \mathrm{CO}_{2} \mathrm{Et}, \mathrm{CN}$

2.

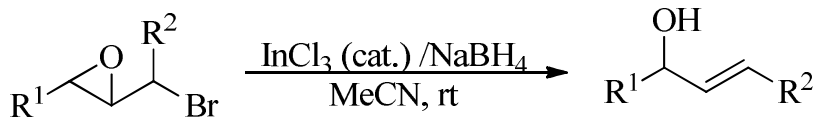

$\mathrm{R}^{1}, \mathrm{R}^{2}=$ aryl, alkyl, $\mathrm{H}$

3.

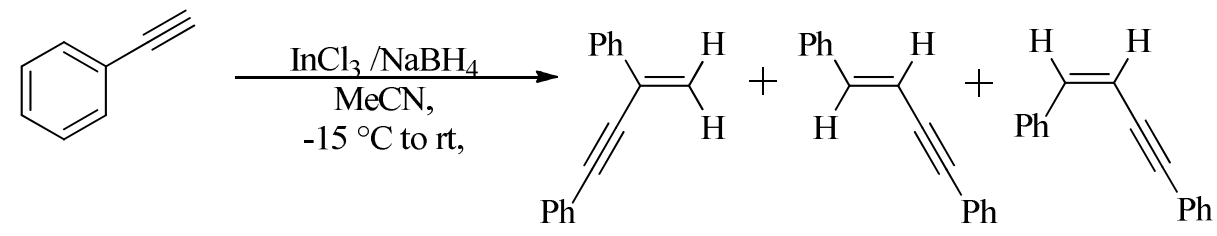

Scheme 25. Dimerization of terminal alkynes to enynes. ${ }^{29}$

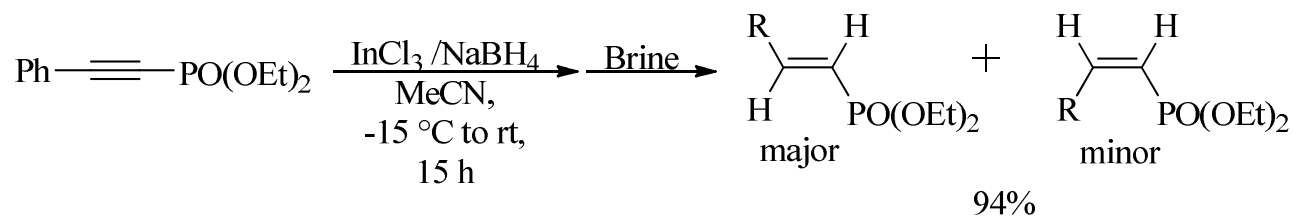

Scheme 26. Synthesis of (E)-2-arylvinylphosphonates using the $\mathrm{InCl}_{3} / \mathrm{NaBH}_{4}$ system. ${ }^{30}$

Since previous reports had not elucidated the origin of these solvent effects, we decided to explore the $\mathrm{InCl}_{3} / \mathrm{NaBH}_{4}$ reagent system further by monitoring the boron species formed during the reaction via ${ }^{11} \mathrm{~B}$ NMR spectroscopy. ${ }^{32}$ Consequently, we reacted a 1:1 molar ratio of $\mathrm{InCl}_{3}$ to $\mathrm{NaBH}_{4}$ in both THF and MeCN and analyzed the supernatant solution by ${ }^{11} \mathrm{~B}$ NMR spectroscopy to probe the identity of the boron species formed in situ (Scheme 27). ${ }^{32}$ 
Table 3. Hydride and solvent effects on the indium catalyzed reduction of halides ${ }^{23}$

\begin{tabular}{rccc}
\cline { 3 - 3 } Entry & Metal hydride & Solvent & Yield $(\%)$ \\
\hline 1 & $\mathrm{Bu}_{3} \mathrm{SnH}$ & $\mathrm{THF}$ & 82 \\
2 & $\mathrm{LiH}$ & $\mathrm{THF}$ & trace \\
3 & $\mathrm{BH}_{3}-\mathrm{THF}$ & $\mathrm{THF}$ & trace \\
4 & $\mathrm{NaBH}_{4}$ & $\mathrm{MeCN}$ & 78 \\
5 & $\mathrm{NaBH}_{4}$ & $\mathrm{THF}$ & 15 \\
6 & $\mathrm{NaBH}_{4}$ & $\mathrm{MeCN}$ & $90^{b}$ \\
\hline
\end{tabular}

${ }^{a} \mathrm{InCl}_{3}(0.1 \mathrm{mmol})$, metal hydride $(1 \mathrm{mmol})$, halide $(1 \mathrm{mmol})$, solvent $(2 \mathrm{~mL}) .{ }^{b} 1.5 \mathrm{mmol}$ of $\mathrm{NaBH}_{4}$ was used.

$$
\begin{array}{cc}
\mathrm{InCl}_{3}+\mathrm{NaBH}_{4} \underset{ }{\stackrel{\mathrm{THF}}{25^{\circ} \mathrm{C}, 1 \mathrm{hr}}} \longrightarrow \mathrm{NaCl}+\mathrm{HInCl}_{2}+\mathrm{BH}_{3} \cdot \mathrm{THF} \\
\mathrm{InCl}_{3}+\mathrm{NaBH}_{4} \underset{ }{\stackrel{\mathrm{CH}_{3} \mathrm{CN}}{25^{\circ} \mathrm{C}, 1 \mathrm{hr}}} \longrightarrow \mathrm{NaCl}+\mathrm{HInCl}_{2}+\mathrm{BH}_{2} \text { complex" }
\end{array}
$$

Scheme 27. Reaction of $\mathrm{InCl}_{3} / \mathrm{NaBH}_{4}$ in $\mathrm{THF}$ and $\mathrm{MeCN}^{32}$

${ }^{11} \mathrm{~B}$ NMR spectral analysis of $\mathrm{InCl}_{3} / \mathrm{NaBH}_{4}$ in THF (Scheme 27, equation 1) revealed the formation of a borane-tetrahydrofuran complex $\left(\mathrm{BH}_{3} \cdot \mathrm{THF}\right){ }^{33}$ When the same reaction was run in MeCN (Scheme 27, equation 2), a significantly different ${ }^{11} \mathrm{~B}$ NMR spectrum was observed. A $\mathrm{BH}_{2}$ species was observed, which we believe is the result of the reduction of the MeCN solvent by borane.

We suggest that the poor reduction of alkyl halides using a catalytic amount of $\mathrm{InCl}_{3}$ along with one equivalent of $\mathrm{NaBH}_{4}$ in THF that was previously reported ${ }^{23}$ is likely to have been due to the inhibition of the catalytic cycle by the in situ generated $\mathrm{BH}_{3}$. THF. Consequently, when a stoichiometric amount of $\mathrm{InCl}_{3}$ was used along with three equivalents of $\mathrm{NaBH}_{4}$, (3-bromopropyl)benzene was fully reduced to $n$-propylbenzene with an isolated yield of $80 \%$, indicating that $\mathrm{BH}_{3}$. THF or the solvent THF has little effect on stoichiometric reductions involving $\mathrm{HInCl}_{2}$. Based on the ${ }^{11} \mathrm{~B}$ NMR spectral data, we postulated that the $\mathrm{InCl}_{3} / \mathrm{NaBH}_{4}$ system in THF should reduce nitriles efficiently. After some optimization we found that 1 equivalent of $\mathrm{InCl}_{3}$ and 3 equivalents of $\mathrm{NaBH}_{4}$ in THF was the optimum ratio to reduce aromatic, heteroaromatic, and aliphatic nitriles the corresponding primary amine (Scheme 28). ${ }^{32}$ 


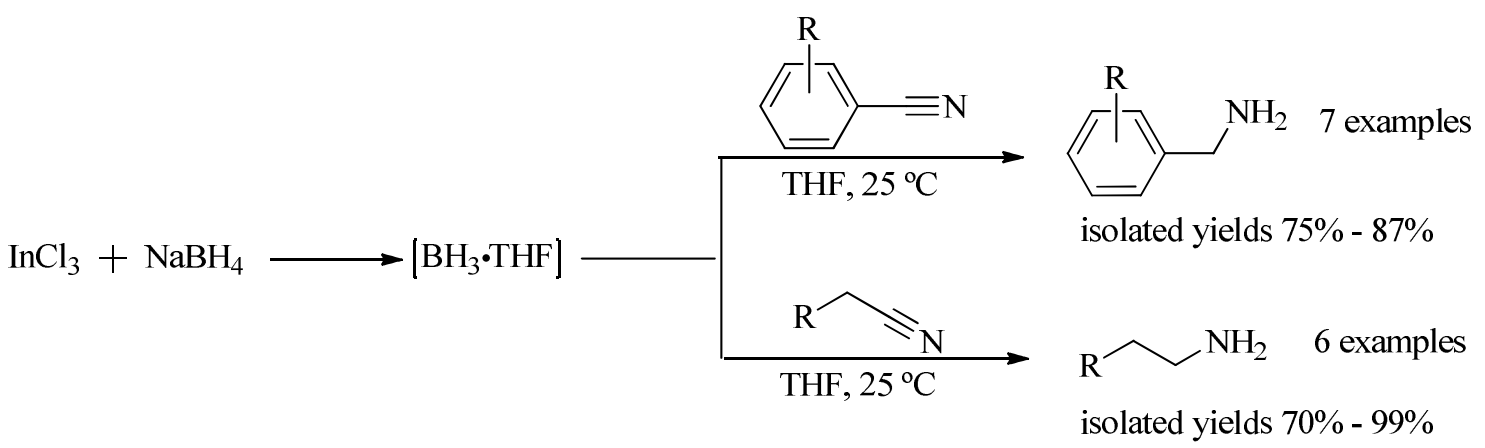

Scheme 28. $\mathrm{InCl}_{3} / \mathrm{NaBH}_{4}$ reduction of aromatic, heteroaromatic and aliphatic nitriles to primary amines. ${ }^{32}$

The $\mathrm{InCl}_{3} / \mathrm{NaBH}_{4}$ system was able to reduce a variety of aromatic nitriles, including aromatic nitriles with electron-donating groups in good to excellent yields (70-99\%). A variety of halogen-substituted aromatic nitriles were also reduced using this simple procedure. Although the reduction of benzyl and aliphatic nitriles is typically more challenging due to the acidity of the $\alpha$-hydrogens, which tend to be deprotonated under some reaction conditions, ${ }^{34}$ the $\mathrm{InCl}_{3} / \mathrm{NaBH}_{4}$ system in THF readily reduced these substrates to their corresponding primary amine in good to excellent yields. Nitriles containing heteroaromatic rings, such as thiopheneacetonitriles, were also nicely reduced using this system.

\subsection{Generation of $\mathrm{HInCl}_{\mathbf{2}}$ using lithium aminoborohydride (LAB)}

We have recently explored alternative methods of producing $\mathrm{HInCl}_{2}$ by the reduction of $\mathrm{InCl}_{3}$ using LAB reagents previously discovered in our laboratory. ${ }^{35}$ The experiments were carried out by reacting one to three equivalents of anhydrous $\mathrm{InCl}_{3}$ with one to three equivalents of lithium dimethylaminoborohydride (MeLAB) in THF for $1 \mathrm{~h}$ at $25^{\circ} \mathrm{C}$. The reactions were then evaluated by obtaining the ${ }^{11} \mathrm{~B}$ NMR spectrum of the supernatant solution under an inert atmosphere. It was discovered that the ratio of $\mathrm{InCl}_{3}$ to $\mathrm{MeLAB}$ played a significant role in the formation of the reducing species (Table 4$){ }^{32}$

When an excess of MeLAB was used (Table 4, entries 1 and 2), the reaction mixture quickly turned dark grey and precipitated colloidal indium metal which aggregated to form a shiny indium nugget. From the weight of the indium metal, it was deduced that indium metal was formed essentially quantitatively in these reactions. Our results indicate that two equivalents of MeLAB reagent were sufficient to fully reduce $\mathrm{InCl}_{3}$ to indium metal in a quantitative manner (Table 4, entry 2). However, when two or more equivalents of $\mathrm{InCl}_{3}$ were used and one equivalent of MeLAB was added slowly over 5 minutes (Table 4, entries 4 and 5), little or no indium metal was generated and only a slight browning of the reaction mixture was observed. ${ }^{11} \mathrm{~B}$ NMR spectroscopy revealed the complete disappearance of the MeLAB quartet at $\delta-15 \mathrm{ppm}$ and the appearance of a corresponding aminoborane $\left[\mathrm{BH}_{2} \mathrm{~N}\left(\mathrm{CH}_{3}\right)_{2}\right]_{\mathrm{n}}$ complex that we believe to be a dimmer, with a triplet at $\delta 5 \mathrm{ppm}^{32}$ 
It was also found that the $\mathrm{HInCl} \mathrm{I}_{2}$ produced using the $\mathrm{MeLAB} / \mathrm{InCl}_{3}$ reagent system possesses similar reductive capabilities to that of $\mathrm{HInCl}_{2}$ prepared via other methods. For example, we were able to reduce aliphatic halides like (3-bromopropyl)benzene to $n$-propylbenzene in $77 \%$ yield (Scheme 29). ${ }^{32}$

Table 4. The $\mathrm{InCl}_{3} / \mathrm{MeLAB}$ System and the production of $\mathrm{HInCl}_{2}$ and $\mathrm{In}^{32}$

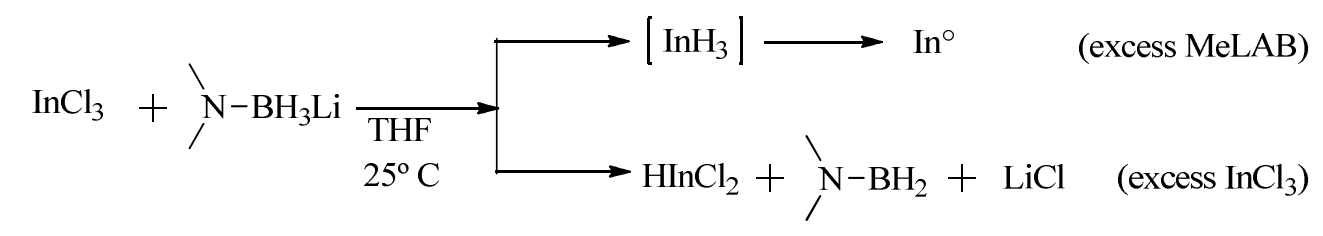

\begin{tabular}{cccc}
\hline Entry & $\begin{array}{c}\mathrm{InCl}_{3} \\
\text { (Equiv.) }\end{array}$ & $\begin{array}{c}\text { MeLAB } \\
\text { (Equiv.) }\end{array}$ & $\begin{array}{c}\text { Isolated Indium } \\
\text { (Equiv.) }\end{array}$ \\
\hline 1 & 1 & 3 & 0.98 \\
2 & 1 & 2 & 0.99 \\
3 & 1 & 1 & 0.41 \\
4 & 2 & 1 & 0.24 \\
5 & 3 & 1 & 0 \\
\hline
\end{tabular}

${ }^{a}$ Reactions were carried out on $1 \mathrm{mmol}$ scale in $10 \mathrm{~mL}$ of solvent.

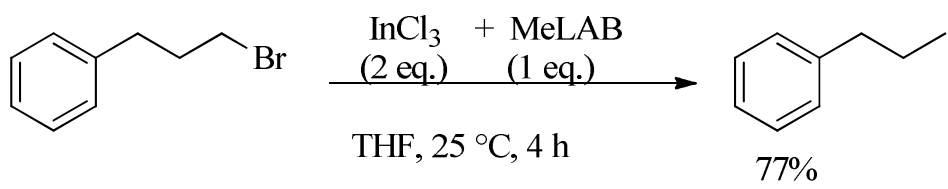

Scheme 29. Carbon-bromine bond reduction using $\mathrm{InCl}_{3} / \mathrm{MeLAB}{ }^{32}$

\subsection{Tandem, selective and partial reduction of halides and nitriles using $\mathrm{HInCl}_{2}$}

As discussed above, dichloroindium hydride can be synthesized by a variety of methods. The method and the reaction conditions utilized can have a profound effect on the reaction outcome. We suggest that these dramatic differences can in part be explained by the reaction of byproducts generated during the synthesis of $\mathrm{HInCl}_{2}$. This allows for the customization of the reductive capabilities depending on the method used to prepare $\mathrm{HInCl}_{2}$ ( $\mathrm{Scheme} 30$ ). 


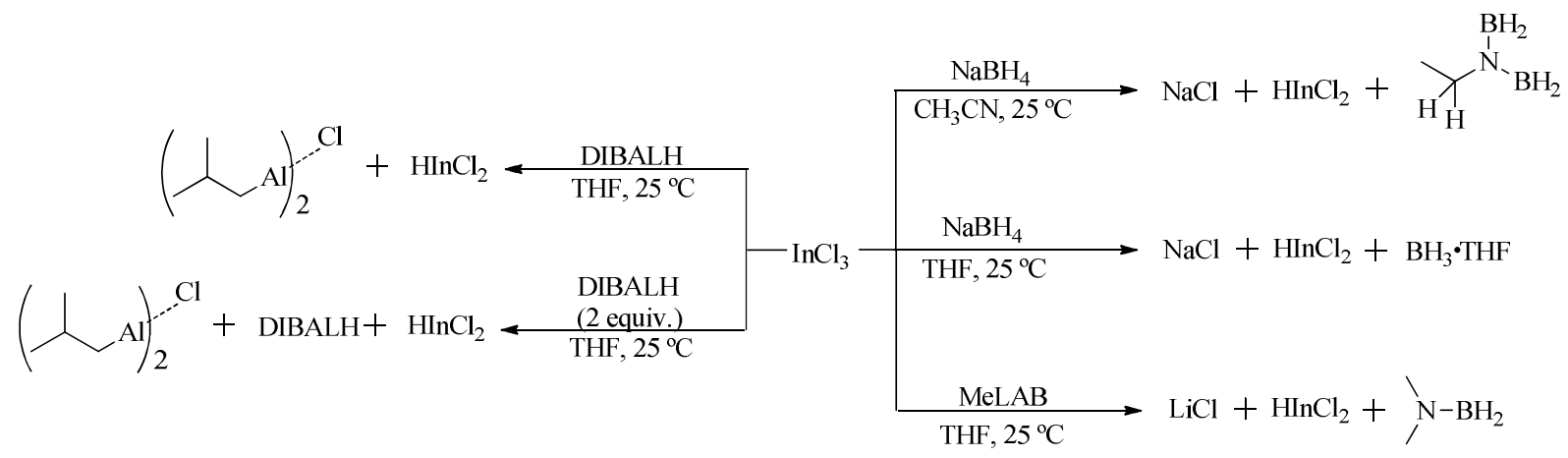

Scheme 30. Various methods of generating $\mathrm{HInCl}_{2}$.

2.6.1 Tandem reductions using $\mathrm{HInCl}_{2}$ and $\mathrm{BH}_{3} \cdot$ THF. While our previous study demonstrated the ability of $\mathrm{InCl}_{3} / \mathrm{NaBH}_{4}$ to reduce nitriles to primary amines utilizing in situ generated $\mathrm{BH}_{3} \cdot \mathrm{THF},{ }^{32}$ we also sought to explore the reductive capabilities of the mixture of $\mathrm{HInCl}_{2}$ and $\mathrm{BH}_{3}$. THF. This was achieved by investigating a tandem reduction sequence that utilized both the $\mathrm{HInCl}_{2}$ and $\mathrm{BH}_{3}$. THF generated in situ from the $\mathrm{InCl}_{3} / \mathrm{NaBH}_{4}$ system (Scheme 31 ).

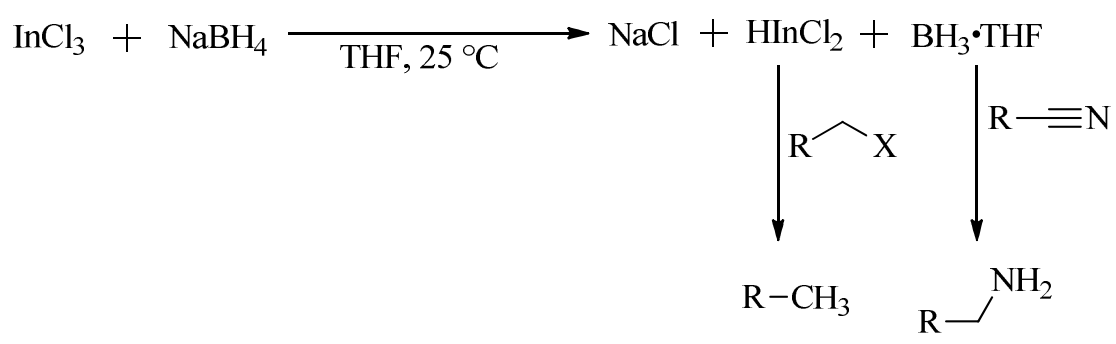

Scheme 31. Generation of $\mathrm{HInCl}_{2}$ and $\mathrm{BH}_{3} \cdot \mathrm{THF}$.

Since $\mathrm{HInCl}_{2}$ is known to reduce alkyl halides, ${ }^{23}$ 4-(bromomethyl)benzonitrile and 4(chloromethyl)benzonitrile underwent the expected tandem reduction to afford 4-methylbenzylamine in isolated yields of $85 \%$ and $65 \%$, respectively. Similarly, using the $\mathrm{InCl}_{3} / \mathrm{NaBH}_{4} / \mathrm{THF}$ system, 6-bromohexanenitrile was found to undergo the tandem reduction of both the halide and nitrile using the $\mathrm{InCl}_{3} / \mathrm{NaBH}_{4}$ system in THF to afford hexan-1-amine in an isolated yield of $68 \%$, clearly demonstrating the reductive potential of $\mathrm{HInCl}_{2}$ and $\mathrm{BH}_{3} \cdot \mathrm{THF}$ generated in situ from the $\mathrm{InCl}_{3} / \mathrm{NaBH}_{4}$ system in THF (Scheme 32). 


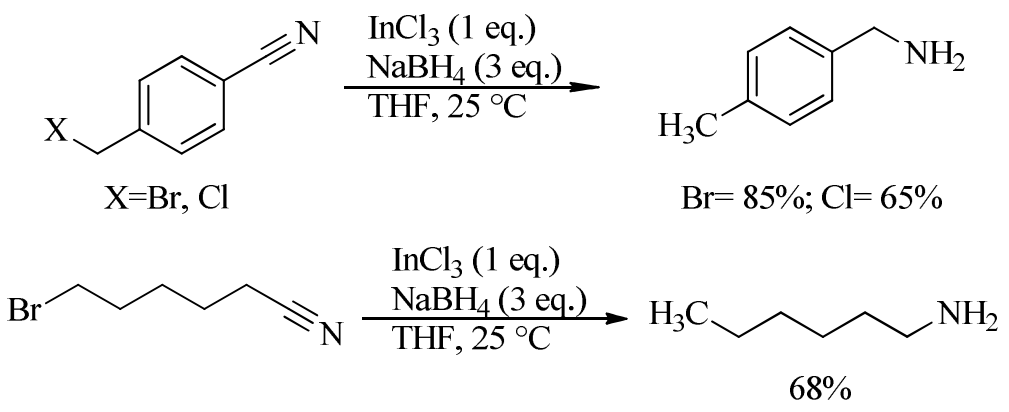

Scheme 32. Tandem reduction of halo nitriles using $\mathrm{InCl}_{3} / \mathrm{NaBH}_{4} / \mathrm{THF}$.

2.6.2 Selective reduction of halides in the presence of nitriles. We next turned our attention to the selective reduction of halides in the presence of nitriles using the $\mathrm{InCl}_{3} / \mathrm{NaBH}_{4}$ system. The main obstacle envisioned for this reaction was the selective scavenging of $\mathrm{BH}_{3}$. THF from the mixture of $\mathrm{HInCl}_{2}$ and $\mathrm{BH}_{3}$.THF. Attempts were made to capture the generated borane with tetramethylethylenediamine (TMEDA), which is known to readily complex with $\mathrm{BH}_{3}$ to form $\left(\mathrm{BH}_{3}\right)_{2}$. TMEDA. ${ }^{36}$ However, TMEDA also tightly complexed $\mathrm{HInCl}_{2}$ and prevented it from reducing carbon-halogen bonds. This result prompted us to revisit the $\mathrm{MeLAB} / \mathrm{InCl}_{3}$ system which previously reduced (3-bromopropyl) benzene to the corresponding $n$-propylbenzene in $77 \%$ yield. We anticipated that this system would give selective reductions of carbon-halogen bonds in the presence of nitriles (Scheme 33).

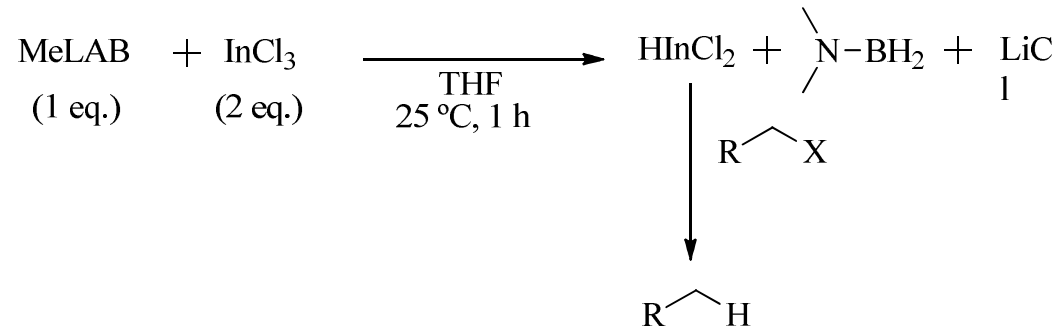

Scheme 33. Generation of $\mathrm{HInCl}_{2}$ with MeLAB.

After some optimization, the $\mathrm{MeLAB} / \mathrm{InCl}_{3}$ system was found to selectively reduce alkyl halides in the presence of nitriles as evidenced by the reduction of 4-(bromomethyl)benzonitrile and 4-(chloromethyl)benzonitrile to $p$-tolunitrile in isolated yields of $70 \%$ and $94 \%$, respectively (Scheme 34).<smiles>[X]Cc1ccc(C#N)cc1</smiles>

$\mathrm{X}=\mathrm{Br}, \mathrm{Cl}$

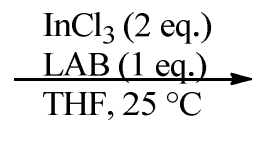

$\mathrm{Br}=70 \% ; \mathrm{Cl}=94 \%$

Scheme 34. Selective reductions using $\mathrm{MeLAB} / \mathrm{InCl}_{3}$. 
As noted earlier, $\mathrm{MeCN}$ was found to be an excellent borane scavenger and generated only $\mathrm{HInCl}_{2}$ from the $\mathrm{InCl}_{3} / \mathrm{NaBH}_{4}$ system. This property of $\mathrm{MeCN}$ along with the ability of $\mathrm{HInCl}_{2}$ to reduce halides was utilized to selectively reduce 4-(bromomethyl)benzonitrile and 4-(chloromethyl)benzonitrile to $p$-tolunitrile in an isolated yield of $98 \%$ and $68 \%$, respectively (Scheme $35)$.

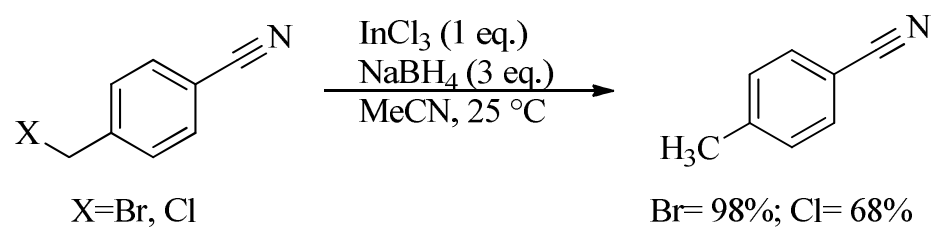

Scheme 35. Selective reduction using $\mathrm{InCl}_{3} / \mathrm{NaBH}_{4} / \mathrm{MeCN}$.

2.6.3 Tandem, selective, and partial reduction of halo-nitriles using DIBAL-H and $\mathrm{InCl}_{3}$. Lastly, generation of $\mathrm{HInCl}_{2}$ using DIBAL-H was also explored and utilized to selectively reduce halides in the presence of nitriles. As previously mentioned, Oshima and coworkers demonstrated the generation of $\mathrm{HInCl}_{2}$ using $\mathrm{InCl}_{3} / \mathrm{DIBAL}-\mathrm{H}$. We were able to utilize $\mathrm{HInCl}_{2}$ generated via Oshima's procedure to selectively reduce 4-(bromomethyl)benzonitrile and 4(chloromethyl)benzonitrile to $p$-tolunitrile in isolated yields of $85 \%$ and $74 \%$, respectively (Scheme 36).

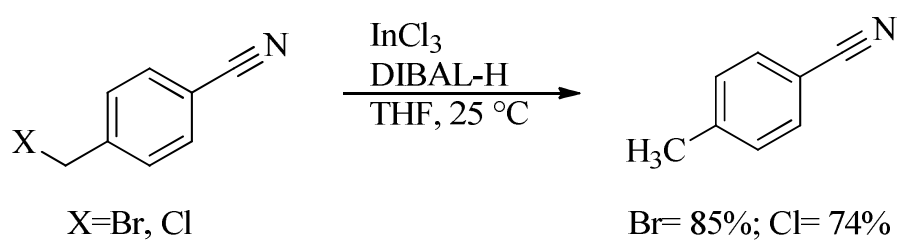

Scheme 36. Selective reduction using $\mathrm{InCl}_{3} / \mathrm{DIBAL}-\mathrm{H}$.

It is well established that DIBAL-H can partially reduce nitriles to aldehydes. ${ }^{37}$ Interestingly, DIBAL-H selectively and partially reduces 4-(bromomethyl)benzonitrile and 4(chloromethyl)benzonitrile to the corresponding aldehydes in very good yields (Scheme 37).

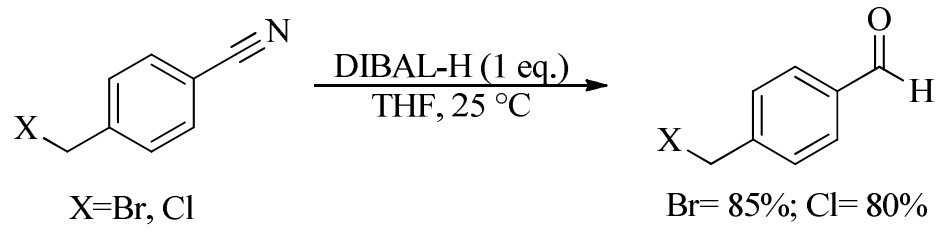

Scheme 37. Selective partial reductions using DIBAL-H. 
Sequential addition of two equivalents of DIBAL-H followed by addition of $\mathrm{InCl}_{3}$ afforded an efficient tandem reduction reaction of halo nitriles. The first equivalent of DIBAL-H partially reduced the nitrile functionality while the second equivalent of DIBAL-H, in conjunction with $\mathrm{InCl}_{3}$, reduced the carbon-halogen bond. This was exemplified by the tandem reduction of 4(bromomethyl)benzonitrile and 4-(chloromethyl)benzonitrile to 4-methylbenzaldehye in $67 \%$ and 63\%, respectively (Scheme 38).

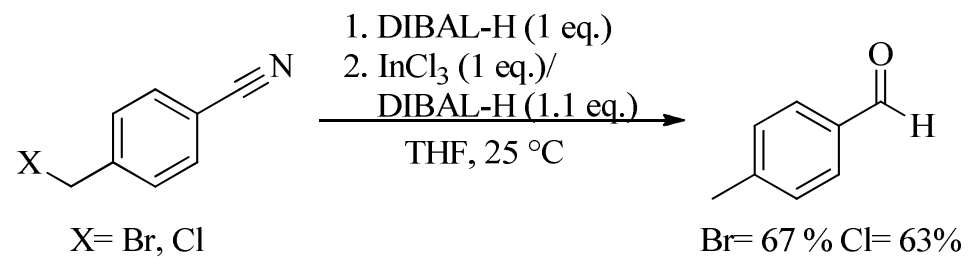

Scheme 38. Tandem partial reduction of nitriles and halides using $\mathrm{InCl}_{3} / \mathrm{DIBAL}-\mathrm{H}$.

\section{Conclusions}

Generation of $\mathrm{HInCl}_{2}$ using a variety of hydride sources, such as: $\mathrm{Bu}_{3} \mathrm{SnH}, \mathrm{Et}_{3} \mathrm{SiH}, \mathrm{NaBH}_{4}$, DIBAL-H, and MeLAB, is comparatively reviewed. The methods of $\mathrm{HInCl}_{2}$ generation and the reaction by-products allowed for tailoring of the systems towards tandem, selective and partial reductions of halo nitriles. The $\mathrm{InCl}_{3} / \mathrm{NaBH}_{4} / \mathrm{THF}$ system was found to efficiently reduce both nitriles and carbon-halogen bonds in a tandem fashion utilizing both $\mathrm{HInCl}_{2}$ and $\mathrm{BH}_{3}$. THF. In comparison, the $\mathrm{InCl}_{3} / \mathrm{NaBH}_{4} / \mathrm{MeCN}$ system, in which acetonitrile scavenges the in situ generated borane and affords the selective reduction of the carbon-halogen bond in halo nitriles. Similarly, the $\mathrm{InCl}_{3} / \mathrm{MeLAB}$ and the $\mathrm{InCl}_{3} / \mathrm{DIBAL}-\mathrm{H}$ systems were also found to selectively reduce the carbon-halogen bond in halo nitriles, while DIBAL-H alone selectively reduced halo nitriles to the corresponding halo aldehyde. The sequential addition of two equivalents of DIBAL-H followed by the addition of an equivalent of $\mathrm{InCl}_{3}$ allowed the partial reduction of halo nitriles to halo imines and subsequent reduction of the carbon-halogen bond to afford the corresponding aldehyde in a one-pot procedure.

\section{References}

1. Brown, H. C.; Schlesinger, H. I.; Ritter, D. M. J. Am. Chem. Soc. 1953, 75, 192.

2. Finholt, A. E.; Bond, A. C.; Schlesinger, H. I. J. Am. Chem. Soc. 1947, 69, 1199.

3. (a) Hudlicky, M. Reductions in Organic Chemistry; John Wiley and Sons: New York, 1984; p 20. (b) Hajos, A. Complex Hydrides; Elsevier: New York, 1979; p 83.

4. Downs, A. J.; Pulham, C. R. Chem. Soc. Rev. 1994, 23, 175. 
5. Vaysek, P. Handbook of Chemistry and Physics: $91^{\text {st }}$ Ed.; Lide, D. R. Taylor \& Francis, Inc. 2010.

6. (a) Wiberg, E.; Dittman, O.; Schmidt, M., Zeitschrift Fur Naturforschung 1957, 12, 57. (b) Wiberg, E.; Dittmann, O.; Noth, H.; Schmidt, M., Zeitschrift Fur Naturforschung 1957, 12, 56. (c) Wiberg, E.; Schmidt, M., Zeitschrift Fur Naturforschung 1957, 12, 54.

7. (a)Yamada, M.; Tanaka, K.; Araki, S.; Butsugan, Y. Tetrahedron Lett. 1995, 36, 3169. (b) Yamada, M.; Tanaka, K.; Butsugan, Y.; Kawai, M.; Yamamura, H.; Araki, S. Main Group Met. Chem. 1997, 20, 241.

8. Miyai, T.; Inoue, K.; Yasuda, M.; Shibata, I.; Baba, A. Tetrahedron Lett. 1998, 39, 1929.

9. Inoue, K.; Ishida, T.; Shibata, I.; Baba A. Adv. Synth. Catal. 2002, 344, 283.

10. (a)Inoue, K.; Yasuda, M.; Shibata, I.; Baba, A. Tetrahedron Lett. 2000, 41, 113. (b) Baba, A.; Shibata, I. Chem. Rec. 2005, 5, 323.

11. (a) Inoue, K.; Sawada, A.; Shibata, I.; Baba, A. Tetrahedron Lett. 2001, 42, 4661. (b) Hayashi, N.; Honda, H.; Yasuda, M.; Shibata, I.; Baba, A. Org. Lett. 2006, 8, 4553.

12. (a) Takami, K.; Yorimitsu, H.; Oshima, K., Org. Lett. 2002, 4, 2993. (b) Takami, K.; Mikami, S.; Yorimitsu, H.; Shinokubo, H.; Oshima, K. J. Org. Chem. 2003, 68, 6627.

13. Takami, K.; Mikami, S.; Yorimitsu, H.; Shinokubo, H.; Oshima, K. Tetrahedron 2003, 59, 6627.

14. (a) Miyai, T.; Onishi, Y.; Baba, A. Tetrahedron Lett. 1998, 39, 6291. (b) Miyai, T.; Onishi, Y.; Baba, A. Tetrahedron 1999, 55, 1017.

15. Miyai, T.; Ueba, M.; Baba, A., Synlett 1999, 182.

16. Yasuda, M.; Onishi, Y.; Ueba, M.; Miyai, T.; Baba, A. J. Org. Chem. 2001, 66, 7741.

17. Shibata, I.; Kato, H.; Ishida, T.; Yasuda, M.; Baba, A. Angew. Chem., Int. Ed. 2004, 43, 711.

18. (a) Hayashi, N.; Shibata, I.; Baba, A. Org. Lett. 2004, 6, 4981. (b) Hayashi, N.; Shibata, I.; Baba, A. Org. Lett. 2005, 7, 3093.

19. Benati, L.; Bencivenni, G.; Leardini, R.; Nanni, D.; Minozzi, M.; Spagnolo, P.; Scialpi, R.; Zanardi, G. Org. Lett. 2006, 8, 2499.

20. (a) Lee, O. Y.; Law, K. L.; Ho, C. Y.; Yang, D. J. Org. Chem. 2008, 73, 8829. (b) Lee, O. Y.; Law, K. L.; Yang, D. Org. Lett. 2009, 11, 3302.

21. Sakai, N.; Fujii, K.; Konakahara, T. Tetrahedron Lett. 2008, 49, 6873.

22. Sakai, N.; Kawana, K.; Ikeda, R.; Nakaike, Y.; Konakahara, T. Eur. J. Org. Chem. 2011, 17, 3178.

23. Inoue, K.; Sawada, A.; Shibata, I.; Baba, A. J. Am. Chem. Soc. 2002, 124, 906.

24. Ranu, B. C.; Samanta, S., Tetrahedron Lett. 2002, 43, 7405.

25. Ranu, B. C.; Samanta, S., Tetrahedron 2003, 59, 7901.

26. Ranu, B. C.; Samanta, S., J. Org. Chem. 2003, 68, 7130-7132.

27. Ranu, B. C.; Das, A.; Hajra, A., Synthesis 2003, 7, 1012.

28. Ranu, B. C.; Banerjee, S.; Das, A., Tetrahedron Lett. 2004, 45, 8579.

29. Wang, C. Y.; Su, H.; Yang, D. Y., Synlett 2004, 3, 561.

30. Wang, C. Y.; Pan, Y. J.; Yang, D. Y. J. Organomet. Chem. 2005, 690, 1705. 
31. Wang, C. Y.; Yan, L.; Zheng, Z. G.; Yang, D. Y.; Pan, Y. J. Tetrahedron 2006, 62, 7712.

32. Saavedra, J. Z.; Resendez, A.; Rovira, A.; Eagon, S.; Haddenham, D.; Singaram, B. J. Org. Chem. 2012, 77, 221.

33. Than, C.; Morimoto, H.; Andres, H.; Williams, P. G. J. Org. Chem. 1995, 60, 7503.

34. (a) Brown, H. C.; Kim, S. C.; Krishnamurthy, S. J. Org. Chem. 1980, 45, 1. (b) Collins, C. J.; Fisher, G. B.; Reem, A.; Goralski, C. T.; Singaram, B. Tetrahedron Lett. 1997, 38, 529-532.

35. (a) Fisher, G. B.; Harrison, J.; Fuller, J. C.; Goralski, C. T.; Singaram, B. Tetrahedron Lett. 1992, 33, 4533-4536. (b) Fisher, G. B.; Fuller, J. C.; Harrison, J.; Alvarez, S. G.; Burkhardt, E. R.; Goralski, C. T.; Singaram, B. J. Org. Chem.1994, 59, 6378.

36. (a) Brown, H. C.; Singaram, B.; Schwier, J. R. Inorg. Chem. 1979, 18, 51. (b) Brown, H. C.; Singaram, B. Inorg. Chem. 1980, 19, 455.

37. Zakharkin, L. I.; Khorlina, I. M. Dokl. Akad. Nauk SSSR 1957, 116, 422. 